\title{
La caricatura simbólica: herramienta formadora del pensamiento crítico
}

\section{The symbolic cartoon: critical thinking forming tool}

\author{
Lina María Medina Rincón * \\ Natalia Villamarin Ferro**
}

Fecha de Recepción: 15 de agosto de 2016

Fecha de Aprobación: 27 de noviembre de 2017

Artículo de reflexión

\section{Resumen}

El pensamiento crítico es hoy una necesidad apremiante en los ambientes pedagógicos. Despertar en nuestros estudiantes una actitud crítico-reflexiva y, a la vez, propositiva nos involucra en transformaciones en las prácticas educativas. La imagen como herramienta eficaz en los procesos de comunicación, permite la potencialización del sujeto creativo y reflexivo. Es así que, se plantea la caricatura simbólica como herramienta para propiciar estrategias de interpretación. El colectivo de la investigación, implementó actividades en estudiantes de primero y once de la Institución Educativa Politécnico “Álvaro González Santana”, apuntando a prácticas pedagógicas que desarrollen el pensamiento crítico. Esta nueva forma de asumir el pensamiento mediante la apreciación del trabajo de los caricaturistas "Matador" y "Goyo", proyecta situaciones en las cuales la función semiótica y metafórica se pluralizan. Metodológicamente, se sustenta en la observación directa, talleres y diarios de campo, que arrojan como resultado el mejoramiento en habilidades de pensamiento crítico.

Palabras clave: pensamiento crítico, imagen, caricatura, educación, estrategias.
* Institución Educativa

Politécnico Álvaro

González Santana-Boyacá, Colombia

linamaria.medina@yahoo.es

**Institución Educativa

Politécnico Álvaro

González Santana-Boyacá,

Colombia

natavife@gmail.com

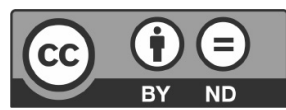




\section{Abstract}

Critical thinking is today a pressing need in pedagogical environments. Awaken in our students a critical-reflective attitude and, at the same time, we engage in purposeful changes in educational practices. The image as an effective tool in communication processes, allows the potentializing of the creative and reflective subject. Thus, the symbolic caricature is proposed as a tool to encourage interpretation strategies. The research group, implemented activities in first and eleventh grade students of the Educational Institution
"Álvaro González Santana", pointing to pedagogical practices that develop critical thinking. This new way of assuming thought through the appreciation of the work of the cartoonists "Matador" and "Goyo", projects situations in which the semiotic and metaphoric function are pluralized. Methodologically, it is based on direct observation, workshops and field journals, which result in the improvement of critical thinking skills.

Keywords: critical thinking, image, caricature, education, strategies. 


\section{Introducción}

\section{"Caricatureando, soñando y transformando"}

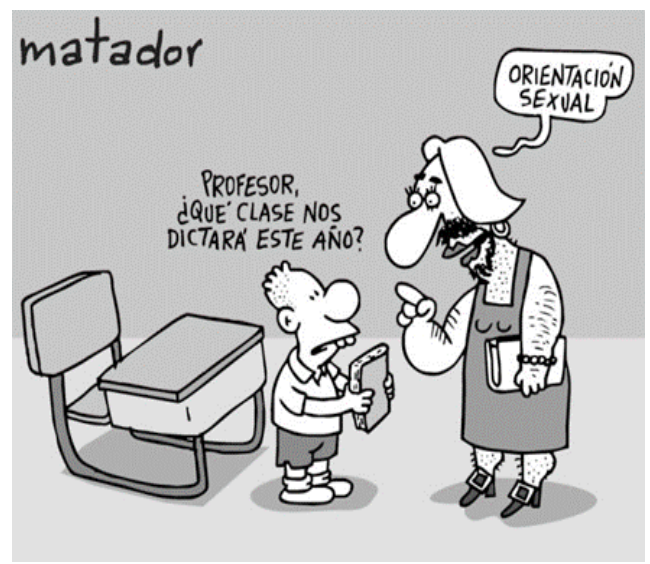

Figura 1. Polémica cátedra LGBT

.Matadorcartoons.blogspot.com.co

La educación en constante transformación de paradigmas, nos exige estar a la vanguardia, innovando en alternativas que faciliten los procesos pedagógicos. La Institución Educativa Politécnico Álvaro González Santana, cuyo modelo de aprendizaje se consolida en el aprendizaje significativo mediado, sugiere en su visión la formación integral, y es de allí donde se desprende la iniciativa de recrear nuevas estrategias llamativas con las cuales seguir el plan de mejoramiento, apuntando hacia el desarrollo del pensamiento crítico.

Este estudio pretende mostrar, de una forma didáctica, humorística y reflexiva, a la caricatura simbólica; aquella que destaca los aspectos sociales y políticos de nuestro entorno y de la que llegamos a encadenar no solo la descripción, sino abstraer más allá de lo que la iconografía nos presenta a través de otros sistemas simbólicos.
Tomando como punto de partida la observación directa en el quehacer docente, maestras de grado primero y once, evidenciamos la necesidad de prácticas didácticas que, cimentadas en la obra de "matador" y "Goyo", conlleven a recontextualizar el pensamiento crítico. Es por ello que, mediante pruebas diagnósticas aplicadas a los dos grupos, logramos consolidar cómo la imagen $-y$, aún más, las caricaturas- es una herramienta poderosa y significativa de la cual podemos valernos para fortalecer procesos.

El carácter dinámico de la caricatura simbólica, permitió capturar, en gran medida, la atención de cada uno de los estudiantes, los cuales mostraron que esta herramienta cargada de expresión iconográfica y textual, conlleva a recrear nuevas concepciones de pensamiento, y que estas ofrecen la oportunidad de potencializar otras habilidades. Entiéndase por iconografía, según González (1991), como: "la ciencia que estudia el origen y la formación de las imágenes, las relaciones de las mismas con lo alegórico y lo simbólico, así como sus respectivas identificaciones por medio de los atributos que casi siempre las acompañan" (p. 15).

Finalmente, el trabajo de campo permitió determinar cómo, tomando un punto de partida en el cual la presencia de la caricatura se tornaba solamente como una observación humorística, llega a transformarse hacia la expresión de ideas a través de nuevas formas. El nuevo crítico ahora, debate, critica, asume un punto de vista, y evidencia nuevas formas en las que propone posibles soluciones. Este crítico 
Una de las mayores tareas de la pedagogía crítica ha sido revelar y desafiar el papel que las escuelas desempeñan en nuestra vida política y cultural. en potencia visiona, de una forma diferente, las formas iconográficas $\mathrm{y}$ crea las propias, con las cuales pretende también demostrar que vale la pena expresarse de una forma diferente.

\section{Soñando Ando, Caricatografía Crítica}

La pedagogía moderna nos involucra en innovadores esquemas que permitan cualificar las prácticas educativas. Es una preocupación inherente al maestro, recrear nuevas formas de visionar el conocimiento, debido a ello, la búsqueda de otras herramientas de expresión que faciliten la interacción desde distintos estadios.

$\mathrm{Al}$ respecto, conviene decir que es importante tomar relevancia acerca de la pedagogía crítica en nuestro interés de vincular la caricatura simbólica en el desarrollo del pensamiento crítico en nuestros estudiantes. Por lo tanto, tomamos al canadiense Peter McLaren, uno de los fundadores de la pedagogía crítica como referente; quien dentro de su ideología nos permite afirmar que una persona crítica está en condiciones de cuestionar su realidad, las circunstancias que determinan su cotidianidad; favoreciendo así su reflexión autocrítica.

Entendemos por esto, que dicha pedagogía crítica, en lo concerniente al campo socio-político, va más allá de cuestionar un sistema con el que se preside una sociedad haciendo las personas cautivas de sí mismas, sino por el contrario, tener la capacidad de abrir su mente y dar paso a la transformación del mundo, basándose en criterios fundamentados en una realidad.
Para Mclaren (1998), a través de su reflexión en "La vida en las escuelas",

Una de las mayores tareas de la pedagogía crítica ha sido revelar y desafiar el papel que las escuelas desempeñan en nuestra vida política y cultural. Sobre todo en la última década, los teóricos de la educación crítica han comenzado a ver a la escuela como una empresa resueltamente política y cultural. (p. 196).

Como docentes, compartimos la responsabilidad de integrar la escuela como protagonista en la comprensión de nuestra cotidianidad social y política, percibida a través de la caricatura, haciendo de nuestros estudiantes personas activas y críticas; donde, partiendo de una imagen y algunas palabras, el educando cuestiona su diario vivir de una manera activa, abierta, analítica, y buscando un cambio desde la individualidad.

La caricatura se proyecta, entonces, como una forma didáctica de representar aspectos significativos; y principal agente que nos ayuda a potenciar el pensamiento crítico de niños y adolescentes en nuestras instituciones educativas. La caricatura y su lenguaje, es uno de los más relevantes, dinámicos y sugestivos fenómenos de la comunicación social. El objetivo de esta herramienta no es solamente el divertir al lector, sino también transmitirle, por medio de la expresión icónica y gráfica, lo que lo abstracto de la escritura no siempre logra expresar.

Priorizando el pensamiento crítico, aquel que nos permite abrir un campo 
amplio de capacidades, como defender puntos de vista, inferir, resolver problemas, comparar, y otros; llevamos al estudiante a reforzar capacidades de pensamiento, a reconstruir un camino de posibilidades en donde sus destrezas cognitivas irán tendientes a fortalecer un sentido crítico. Según lo anterior, se evidencia la importancia de desarrollar en los estudiantes, una nueva concepción del pensamiento, hacia el análisis de su contexto social, familiar y educativo, expresando a través de imágenes como alternativa en el desarrollo de habilidades comunicativas, en el diseño y fundamentación teórico-práctica de los talleres planteados.

NIVELES DE PROCESAMIENTO DE LA INFORMACIÓN

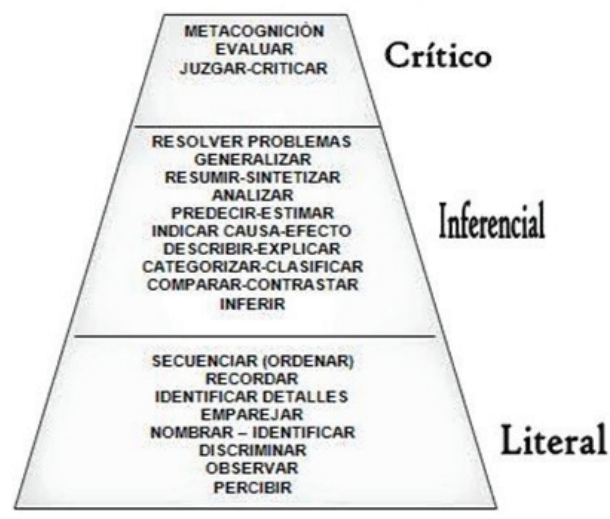

Figura 2. Técnicas y estrategias del pensamiento crítico.

Fuente: Priestley, 2015 p. 37

De acuerdo con el análisis de la pirámide de Maureen Priestley, "Técnicas y estrategias del pensamiento crítico" (Priestley, 2015), conviene resaltar que al ser contrastada con las diferentes actividades realizadas y en las diferentes fases, nuestros estudiantes se encuentran en niveles de procesamiento de la información tanto literal como inferencial, y muchos en el nivel crítico al cual se pretende arribar en un mayor porcentaje.

Bajo el paradigma de comprobar si como docentes podemos "enseñar a pensar" para llegar a ser pensadores críticos, como lo plantea Priestley et al. (2015); se concluye que, indiscutiblemente, se puede orientar a los educandos para tal fin, forjando a través de actividades de interés un nivel de crítica que les permita formular interrogantes con claridad y precisión; analizar información relevante desde ideas abstractas, concluir a través de criterios con fundamento, pensar de forma abierta y a través de una comunicación efectiva; en nuestro caso, partiendo de la caricatura como herramienta que forja el pensamiento crítico.

En la etapa de identificación de posibles herramientas con las cuales lograr resultados óptimos en cuanto al desarrollo del pensamiento crítico, la caricatura en general como instrumento de creación y gracias a su carácter social y político, posibilita en gran medida involucrar al actor que observa, interpreta y luego propone, gracias a que las situaciones representadas hacen parte de nuestro entorno y de nuestro diario vivir. En relación con ello, Vygostky (1932), plantea que "los procesos psicológicos superiores, como la percepción, el razonamiento lógico, el pensamiento y la memoria, se encuentran mediados por herramientas, instrumentos, que son de creación social y como productos de la actividad humana a lo largo de su historia" (p. 94).
Bajo el paradigma de comprobar si como docentes podemos "enseñar a pensar" para llegar a ser pensadores críticos, como lo plantea Priestley et al. (2015) 
En cuanto al trabajo colaborativo, es necesario enfatizar que en los ambientes creativos, y poseedores del poder dinámico de la imagen, se facilita en gran medida la creatividad. Es así que, en los talleres implementados se evidenció la interacción de los estudiantes para la consecución activa de nuevas ideas, colaborar juntos para desarrollar una visión crítica del mundo en que vivimos, "una nueva pedagogía donde los educadores y los educandos trabajan juntos para desarrollar una visión crítica del mundo en el que viven" (Freire, 2006, p. 56).

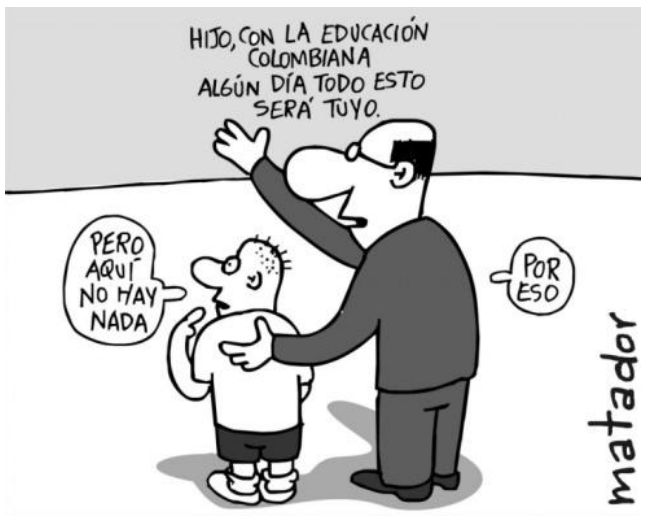

Figura 3. La Educación Colombiana según Matador

Fuente: Matadorcartoons.blogspot.com.co

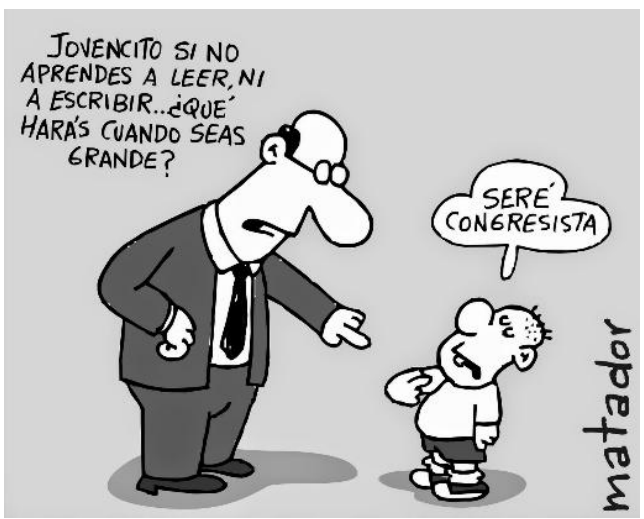

Figura 4. Seré congresista

Fuente: Matadorcartoons.blogspot.com.co
La imagen siempre ha sido una herramienta eficaz en los procesos de comunicación; sin embargo, las maneras de producirla y movilizarla han cambiado, pues el desarrollo de medios tecnológicos permite que, en nuestra época, esta sufra un proceso de densificación, es decir, de expansión de su presencia en espacios tanto públicos como íntimos. Aunado a ello, la caricatura es la herramienta que en mayor porcentaje anima hacia la reflexión y producción de nuevas prácticas, de ello son evidencia la figura 3, en la cual se hace una satírica crítica de nuestra educación actual y se contrasta con la imagen titulada "Seré congresista", figura 4.

Son diversos los conceptos sobre caricatura planteados por teóricos de distintas áreas, a la vez, enfocados desde indeterminados contextos, expectativas y desde tiempos remotos hasta los actuales; teniendo esta un carácter dinámico y transformador, la propuesta se apoya en definiciones como:

La caricatura, es esencialmente una de las formas de sátira, que se expresa fundamentalmente a través de una representación gráfica, casi siempre acompañada por una leyenda escrita o por uno o varios, globos o inscripciones. La caricatura, es una manera de desenmascarar, criticar o atacar a una persona, familia, partido, clase social, institución, gobierno, situación, nación o etnia, destacando por lo común sus aspectos negativos o ridículos (Pérez Vila, 1979, pp. 5-6).

Esta perspectiva se hace amplia al ser utilizada a través de experiencias 
pedagógicas y suele adaptarse por su simbología en actividades prácticas en el aula de clase. Por ejemplo, ver figura 1 en la cual se hace referencia a una problemática actual que involucra el ámbito social y pedagógico y que representa sarcasmo a una problemática educativa vivenciada en el aula de clase.

Para profundizar en el análisis de la caricatura en nuestro país, cabe mencionar una breve historia de la caricatura colombiana que se remonta al siglo XIX, cuando un grabado de Simón Bolívar y Francisco de Paula Santander se representó durante la Constitución de ese entonces. Después, aparece la caricatura en gacetas, que simboliza la época de la reconquista. Cerca de los años 30 del siglo XX, se hace más fuerte la caricatura, ya que se tratan temas sociales, políticos y económicos.

Actualmente, a través de imágenes y algunas palabras, se enfatiza en las situaciones de trasfondo político, social, económico y cotidiano de un país que, a diario, genera noticias que se transportan a un pliego o dibujo informativo, de manera jocosa e invectiva.

\section{Semiótica, Metáfora y Simbología}

Profundizando en el aspecto semiótico de la imagen y su función persuasiva, apuntamos hacia la caricatura simbólica dentro de la lectura en el ámbito escolar. La representación gráfica y textual de primera mano, extrae del alumno sus conocimientos previos, habilidades y estrategias de interpretación para, luego, involucrarse en su propia producción, aquella donde se aporta la autoconstrucción del sentido. En este orden de ideas, el receptor ha encontrado toda una fascinación ideológica, un texto del cual robar emociones, una lectura plural que le invita a compartir significados, una expresión metafórica de la cual arrastrar ideologías.

La caricatura y su sentido simbólico, se presenta como un sistema de significación con código propio y específico; como semiótica connotativa. Este sistema de signos puede tener más de un sentido y supone la presencia de códigos en los que se produce una amplitud de significación, y un sentido comunicativo funcional más que un sentido de estética.

Así pues, es Eco (1973) en su definición hacia la historieta, quien sustenta las particularidades de la caricatura, cuando afirma que,

es un producto cultural ordenado desde arriba, y que funciona según la mecánica de la persuasión oculta, presuponiendo en el lector una postura de evasión que estimula de inmediato las veleidades paternalistas de los organizadores... Así los cómics en su mayoría reflejan la implícita pedagogía de un sistema y funcionan como refuerzo de los mitos y valores vigentes. (p. 299).

Enfatizando en lo semiótico, en lo concerniente a los códigos y a la manera como los signos se articulan como texto simbólico para construir sentido, Bustos (2000) afirma que

se trata de estudiar en los referentes de los signos verbales y no verbales, no tanto la verdad que denota en cada enunciado sino más bien
Actualmente, a través de imágenes y algunas palabras, se enfatiza en las situaciones de trasfondo político, social, económico y cotidiano de un país que, a diario, 


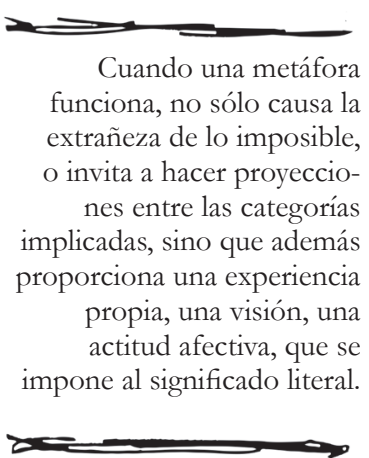

su significado y sentido cultural; ideológico, para el análisis de los contenidos, del significado de las imágenes en los diversos contextos sociales, históricos y politicos. ( $\mathrm{p}$. 31).

El complemento ideológico de toda esta carga narrativa, se aloja evidenciado en la metáfora, aquella que comparte el poder de imponer una visión determinada de una cosa con las imágenes en general; Para Carroll, (1994)

cuando una metáfora funciona, no sólo causa la extrañeza de lo imposible, o invita a hacer proyecciones entre las categorías implicadas, sino que además proporciona una experiencia propia, una visión, una actitud afectiva, que se impone al significado literal. Cuando las imágenes se consideran como ilustraciones de metáforas verbales, cuando se conciben como fuente de "mucha" información, se deja intacta su fuerza como metáfora. Una imagen puede presentar composiciones imposibles, invitar a la comparación de categorías y tener la fuerza de la evidencia sin necesidad de ser metafórica". (p. 214).

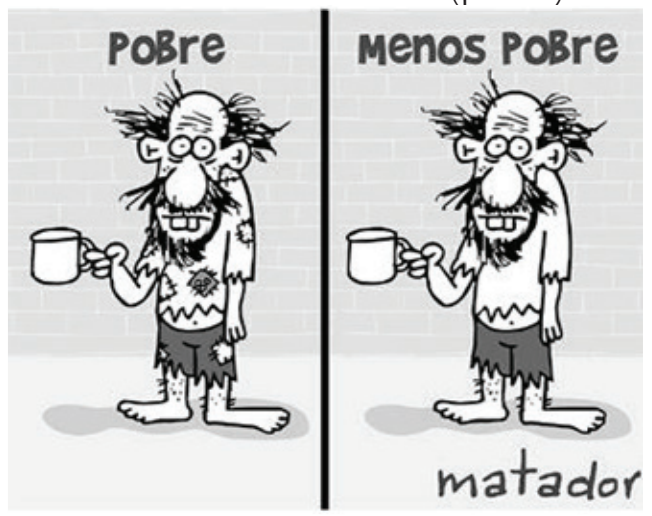

Figura 5. Reducción de la pobreza Matadorcartoons.blogspot.com.co

De lo anterior se deduce que, en las diferentes clasificaciones de este género, es la caricatura simbólica la que mayor potencial reflexivo, metafórico y afectivo aporta hacia el desarrollo del pensamiento crítico en nuestra práctica pedagógica, como se evidencia en las figuras 5 y 6 . En nuestro país, esta representación es trabajada por grandes maestros que, con su obra, muestran diversas percepciones de nuestra realidad social, política y cultural. De acuerdo con las expectativas planteadas en el proyecto, es el maestro Gregorio Gómez Acosta "Goyo" (ver figura 7), quién a nivel regional aporta con sus trazos directos sobre esta iniciativa. Por su parte, Julio César González "Matador" (ver figura 8), con su exquisito trabajo, pinta en caricatura las realidades de nuestro contexto nacional.

"Goyo" es caricaturista del periódico regional "Entérese", en la ciudad de Sogamoso, quien expresa a través de sus dibujos y mensajes escritos, la realidad

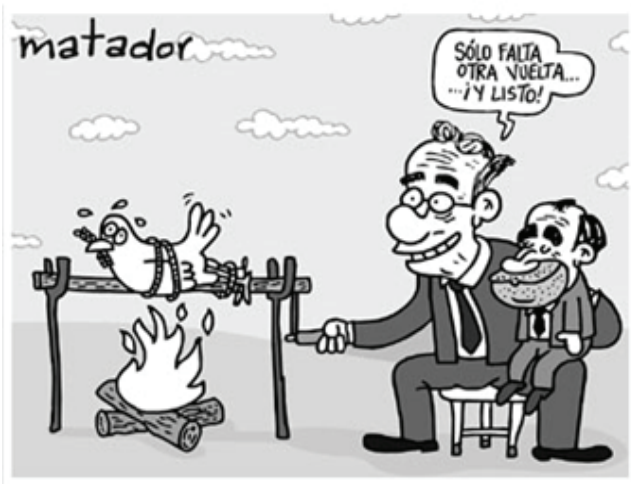

Figura 6. Solo falta una vuelta y listo Matadorcartoons.blogspot.com.co 


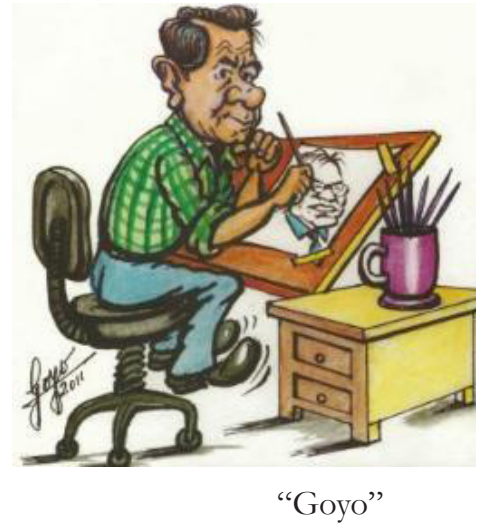

Figura 7. Archivo Periódico Entérese

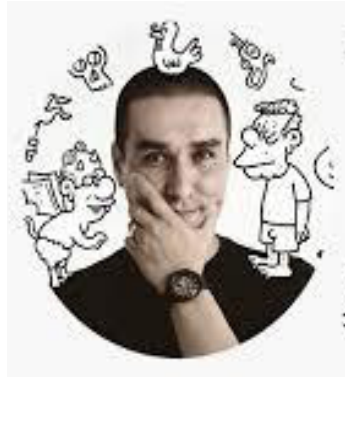

"Lo más jarto era aprenderse las fechas históricas de memoria. Es más fácil leer la historia con cierta dosis de humor y sarcasmos"

Julio César Gomeślez - ematadorelfiempe

\section{"Matador"}

Figura 8.Matadorcartoons.blogspot.com.co

de nuestro contexto político y social, visto de forma sarcástica y que facilita la apreciación de los lectores. Este artista de la sátira caricaturesca, por pertenecer a nuestro contexto próximo, ha sido gran apoyo en cuanto a la interacción con los estudiantes y el equipo de investigación.

Por su parte, "Matador" es un notable publicista y caricaturista colombiano que grafica, con humor y sarcasmo, a través de sus "mamarrachos" como él los llama; la realidad de un país atiborrado de noticias. Así como él lo afirma, "Entender la política no es tan difícil, porque se trata de entender las pasiones del ser humano", Revista Semana, (2014, agosto 23, párr 4). Se logró, entonces, inquietar en los estudiantes una manera amena y responsable de percibir la realidad política y social de nuestro entorno.

\section{Caricatografía y sus Alcances}

Definir "pensamiento crítico" es tan complejo, que es preciso aclarar que no se pretende dar una definición del mismo, sino proponer la caricatura como una herramienta que permite a los estudiantes pensar de una manera crítica, es decir, que demuestre que son capaces de cuestionar lo orientado aportando con argumentos dicho aprendizaje o percepción de su entorno.

Evidenciamos en nuestra práctica pedagógica, falencias en la forma como el estudiante interactúa con el conocimiento; algunos, en forma transcriptora de textos, fundamento de la pura repetición; y otros, con tradicionales formas amañadas, donde la producción de ideas queda a un nivel lejano de interpretación.

La propuesta se fortalece en las bases metodológicas de la investigaciónacción, cuyo fin se fundamenta en convertir en centro de atención lo que ocurre en la actividad docente cotidiana, al diagnosticar y mejorar aspectos pedagógicos. Con este propósito, se toma como referencia dos grupos base, uno a nivel de grado primero, con edades que oscilan entre 6 y 7 años; y otro, con estudiantes de grado once, adolescentes que en su mayoría están en la edad de
Definir "pensamiento crítico" es tan complejo, que es preciso aclarar que no se pretende dar una definición del mismo, sino proponer la caricatura como una herramienta que permite a los estudiantes pensar de una manera crítica 
los 16 años. Dos grupos heterogéneos, de la Institución Educativa Politécnico "Álvaro González Santana" de la ciudad de Sogamoso, que pertenecen a un mismo contexto geográfico, y proyectan la diversidad de sus formas creativas a través de la crítica.

El objetivo, entonces, no es comparar cómo se desarrolla el pensamiento crítico en cada muestra, sino reflexionar en nuestras prácticas pedagógicas, y cómo en cada edad $-\mathrm{y}$ de diferente forma- los esquemas de pensamiento logran ser potencializados.

Con respecto a la experiencia con los estudiantes del grado primero (108), se realizaron una serie de actividades en clase, que permitieron apreciar el agrado y naturalidad con la que los niños y niñas interpretan imágenes: señalización, cuentos en dibujos, historietas, y otras que permiten dar paso a la fluidez de expresión oral acerca de sus apreciaciones e interpretaciones.

Por consiguiente, fue y seguirá siendo un reto motivar a los estudiantes a ser "pensadores críticos ideales", en la apreciación de los mensajes que se transmiten a través de la caricatura; más puntualmente, en la caricatura simbólica, donde los niños dan un claro análisis de forma abierta acerca de lo que ellos y ellas captan sobre nuestra realidad social, política y económica de una forma divertida (ver figura 9); ya que los educandos en esta etapa de niñez se encuentran inmersos y absorbidos por la imagen como medio de interpretación de diversos contextos.

De acuerdo con la pauta de clasificación establecida por Pristley y a las guías aplicadas en el grado primero, los estudiantes en su gran mayoría se encuentran en el nivel "Literal", donde ellos:

- Nombran e identifican algunos mensajes partiendo de las caricaturas simbólicas presentadas, y expresan con sus palabras nuestra realidad sociopolítica.

- Recuerdan después de haber escuchado las percepciones de sus compañeros, un orden en la narración de dichas apreciaciones, llegando a pequeñas conclusiones acerca de lo que ven a través de esas imágenes y las pocas palabras que en ella se muestran.

También, se percibe en algunos estudiantes un nivel "Inferencial" básico, como:

- Comparación y contrastación de algunas opiniones, descripción y explicación de situaciones y diálogo acerca de causa-efecto en circunstancias del contexto político y social.

En el grupo de estudiantes de grado once (1103), luego de un diagnóstico en el cual se identificaron los intereses narrativos mediante un taller práctico, se evidenció que entre el cuento, la poesía, el emoticón y otras formas significativas; es la imagen la forma más llamativa y práctica, y con la cual se logra explorar en habilidades no solo de interpretación, sino de proposición crítica.

A través de los diferentes talleres 


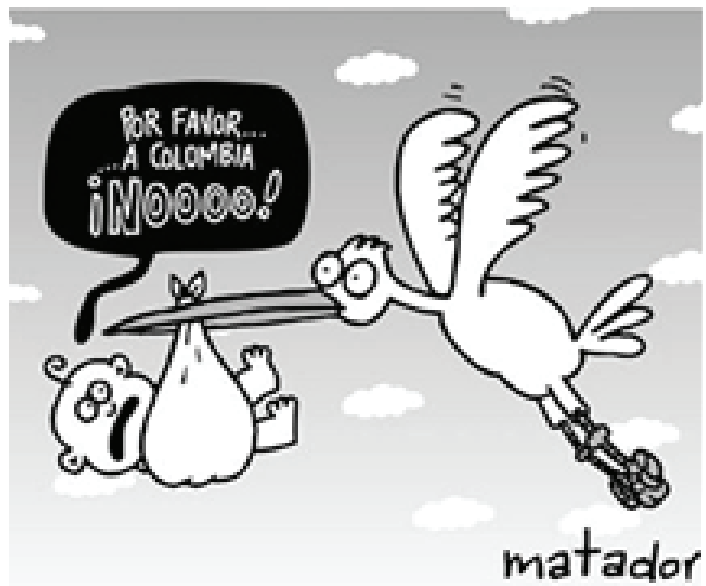

Figura 9. El arribismo es una tragedia nacional

Matadorcartoons.blogspot.com.co

aplicados, se ha logrado fortalecer competencias comunicativas orales y escritas, y un sinnúmero de habilidades de expresión gráfica. En cuanto a los niveles de procesamiento de la información (Priestley et al., 2015), se ha fortalecido la fase literal en cuanto a la percepción, observación, identificación y otras técnicas de análisis; se evidencia la diferencia que hay al seguir patrones de identificación y ordenamiento.

El cuanto a la fase inferencial, cabe resaltar una nueva forma de describir, inferir, explicar, contrastar, entre otras; no solo los textos narrativos de nuestro quehacer pedagógico, sino aprendiendo a ver más allá de la forma tradicional, a la imagen como una herramienta didáctica de expresión ideológica. En la fase crítica, es en donde convergen en mayor medida las expectativas en cada actividad, los estudiantes han puesto empeño en sobrepasar los dos primeros niveles que le han facilitado producir información que ha encontrado relevante. Es así que, el objetivo de

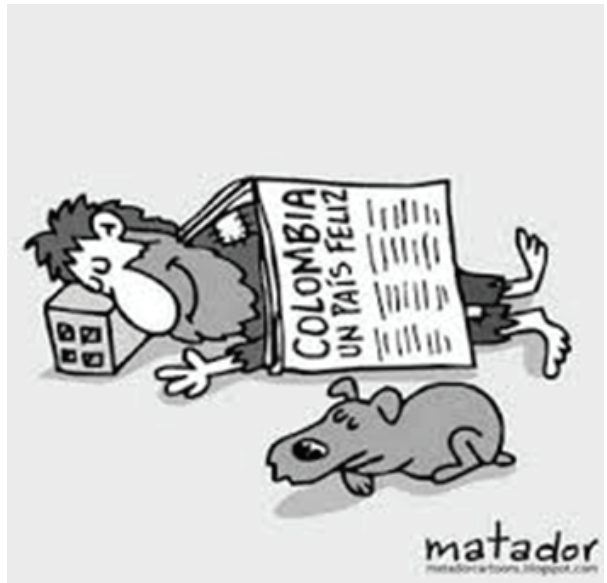

Figura 10. La felicidad colombiana Matadorcartoons.blogspot.com.co

cada uno de los talleres pretende que, a partir de una situación humorística presentada en la caricatura simbólica, logre evaluar, juzgar, criticar y proponer, desde su postura particular, situaciones de nuestra cotidianidad. (ver figura 10).

La implementación de estas actividades creativas, ha mostrado un avance en cuanto a la transformación de esquemas de trabajo. El estudiante es ahora protagonista en temas de debate, y participa en socializaciones activas como mesa redonda, conversatorio, cine foro, entre otros. Ha logrado fortalecer sus capacidades en lectoescritura, ya que se ha convertido en un cuidadoso empleador de grafías, el cual pone especial interés en ampliar su vocabulario, adecuar la ortografía, signos de puntuación y, cada día, fortalecer su hilo narrativo para poder ahora proponer su punto de vista.

Ya que los talleres fueron diseñados para fortalecer el pensamiento crítico de diversas maneras, el alumno disfruta
La implementación de estas actividades creativas, ha mostrado un avance en cuanto a la transformación de esquemas de trabajo. 
leyendo, escribiendo, dibujando y recreando nuevas prácticas pedagógicas. Esto también le permitió valorar el trabajo en equipo, crear vínculos afectivos, y socializar y hacer partícipe a la comunidad educativa.

De igual manera, se hace relevante la identificación de habilidades innatas en cada uno de los educandos, oradores escondidos, escritores anónimos, potentes críticos sociales, políticos en semilla, caricaturistas de las aulas y perseguidores de sueños que muestran valores inimaginables de concebir en una clase monótona. Aunado a ello, la participación de la comunidad educativa en general, resaltando la interacción de los padres de familia quienes se ven involucrados en el trabajo práctico y ayudan en la interpretación y proposición de algunas prácticas caricaturescas.

La caricatura simbólica y su trasfondo, despierta en cada estudiante un panorama amplio de posibilidades de opinión, para soportar ideas y recrear oportunidades de cambio e involucrarse en una solución; al menos desde su realidad y contexto, que le permitirán formular interrogantes con claridad y precisión; analizar información relevante desde ideas abstractas, concluir a través de criterios con fundamento, pensar de forma abierta y a través de una comunicación efectiva.

A manera de colofón, la caricatura y el aporte que brinda en cada una de sus representaciones simbólicas, fueron base de experiencias académicas productivas, humorísticas, imaginativas y, a la vez, una chispa para el fortalecimiento de destrezas que motivaron hacia prácticas dinámicas y propositivas. Ahora, el niño y adolescente impregnado de este recurso posee una visión crítica, una versión imaginativa del cómo expresar su opinión, de desenmascarar con sus aportes, de debatir acerca de sus prioridades y de aportar al mundo con su particular forma de soñar.

Esta experiencia permitió evidenciar que la caricatura simbólica es una herramienta de transformación creativa, que fortalece habilidades críticas; y que, gracias a su carácter reflexivo, dinámico y humorístico, permite nuevos esquemas didácticos en los que prima la creatividad y la puesta en escena de nuevas formas propositivas.
La caricatura simbólica y su trasfondo, despierta en cada estudiante un panorama amplio de posibilidades de opinión, para soportar ideas y recrear oportunidades de cambio e involucrarse en una solución 


\section{Referencias}

Bustos, H. (2000). Para entender historietas. Cuadernos de Lingüística Hispánica, (5). Tunja: Universidad Pedagógica y Tecnológica de Colombia.

Carroll, N. (1994). Visual Metaphor. En J. Hintikka (ed.), Aspects of Metaphor (pp. 189-223), Dordrecht: Kluwer Academic Publisher.

Eco, U. (1973). El signo. Barcelona: Editorial Labor.

GonzÁlez de Zarate, J.M.(1991). Método Iconográfíco. Vitoria: Gastefz.

Freire, P. (2006). Pedagogía del oprimido. México: Siglo XX editores.

McLaren, P. (1998). La vida en las escuelas. Una introducción a la pedagogía crítica en los fundamentos de la educación. México: Editorial Siglo XXI.

Pérez VILA, M. (1979). La caricatura política en el siglo XIX. Venezuela: Lagoven. Priestley, M. (2015). Técnicas y estrategias del pensamiento crítico. México: Trillas. Vygotsky, L. (1932). La construcción social del pensamiento. México: Grijalbo.

\section{Cibergrafía}

https://www.eltiempo.com/opinion/caricaturas/matador

http://www.semana.com/gente/articulo/matador-el-agudo-caricaturista/400084-3

Matadorcartoons.blogspot.com.co 